\title{
Doses e épocas de aplicação de nitrogênio na suscetibilidade do arroz à temperatura baixa na fase reprodutiva
}

\author{
Nitrogen doses and timing on rice susceptibility to low temperature in reproductive stage
}

\author{
Ramón Méndez Larrosa ${ }^{\mathrm{I}}$ Enio Marchesan $^{\mathrm{II}}$ Leandro Souza da Silva $^{\mathrm{III}}$ Luis Antonio de Avila ${ }^{\mathrm{II}}$
}

\section{RESUMO}

A aplicação de nitrogênio $(N)$ deve afetar a sensibilidade das plantas de arroz quando submetidas ao frio na fase reprodutiva. Assim, foram instalados dois experimentos em casa de vegetação, no Instituto Nacional de Investigação Agropecuária (INIA), INIA Treinta y Tres, Uruguai, na safra agrícola 2007/08. O primeiro experimento teve o objetivo de determinar o efeito da época e o segundo, o efeito de dose de aplicação de $N$ sobre a suscetibilidade de plantas de arroz irrigado à temperatura baixa na fase reprodutiva. Realizou-se um experimento bifatorial em delineamento inteiramente casualizado (fator A: épocas ou doses de aplicação de $\mathrm{N} e$ fator B: aplicação ou não de frio nos dois experimentos), com quatro repetições. No experimento 1 , os tratamentos do fator $A$ foram a aplicação de $N\left(30 \mathrm{~kg} \mathrm{ha}^{-1}\right)$ nos estádios V4, V5, V6, V7, $V 8, R 0, R 1+4$ dias e a testemunha sem $N$ em cobertura. Nesse experimento, os tratamentos que receberam $N$ de V4 a V8

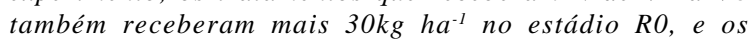
tratamentos que receberam $N$ nos estádios $R 0$ e $R 1+4$ dias também receberam $30 \mathrm{~kg} \mathrm{ha}^{-1}$ no estádio $\mathrm{V} 4$. No experimento 2, o fator A foram níveis de $\mathrm{N}$ de $0,23,46$ e $69 \mathrm{~kg} \mathrm{ha}^{-1}$ de $\mathrm{N}$ no estádio V4 mais uma aplicação de $23 \mathrm{~kg} \mathrm{ha}^{-1}$ no estádio RO e as mesmas doses em $R 0 \mathrm{com} 23 \mathrm{~kg} \mathrm{ha}^{-1}$ no estádio $\mathrm{V} 4$, mais uma testemunha sem aplicação de $N$ nos dois estádios. No tratamento com frio, as plantas foram submetidas a $12,5^{\circ} \mathrm{C}$ durante sete horas em quatro noites quando o colar da folha bandeira ficou com a mesma altura que o colar da folha anterior. Foram avaliados os seguintes parâmetros: a percentagem de esterilidade de espiguetas, o índice SPAD, realizado aos três, 10 e 16 dias após o tratamento do frio no estádio R2-R3, a produtividade de grãos por vaso, o número de panículas por balde e a massa de mil grãos. A esterilidade de espiguetas não foi influenciada pela época, pela dose de aplicação de $\mathrm{N}$ ou pelo tratamento de frio, mas encontrou-se efeito temporário do frio no índice SPAD com atraso na emergência de panículas. Não há necessidade de ajustes da adubação nitrogenada para essa variedade mesmo quando há expectativa de frio no Uruguai.

Palavras-chave: arroz irrigado, frio, índice SPAD.

\section{ABSTRACT}

Nitrogen doses and timing of topdressing application affects the sensibility of rice plants to low temperature in reproductive stage. For these reasons it were installed two experiments with the objective of determining the effect of nitrogen topdressing application doses and timing on the susceptibility of rice plants to low temperature in the reproductive phase. The experiments were sowed in 2007/08 growing season in a greenhouse at Instituto Nacional de Investigação Agropecuária (INIA), INIA Treinta y Tres, Uruguay, with INIA Olimar cultivar. In both experiments, a factorial experiment was carried out in a completely randomized design, with four replications (factor A: stages or rates of $N$ application and factor $B$ : temperature treatment, with or without cold). In the experiment 1 the treatments of factor $A$ were $N$ application of $30 \mathrm{~kg} \mathrm{ha}^{-1}$ in $\mathrm{V} 4, \mathrm{~V} 5, \mathrm{~V} 6, \mathrm{V7}, \mathrm{V8}, \mathrm{RO}, \mathrm{R} 1+4$ days and an untreated check without $N$ in topdressing. In experiment 2, the factor $A$ was doses of $N: 0,23,46$ and $69 \mathrm{~kg} \mathrm{ha}^{-1}$ in V4 stage and the same levels of $N$ in $R 0$ stage plus a check without $N$ in topdressing. The plants were treated with $12.5 \mathrm{C}$ during seven hours for four nights when the collar of the flag leaf was at the same height of the previous leaf. The following aspects were evaluated: grain yield; spikelet sterility; SPAD index at three, ten and sixteen days of low temperature treatment; number of panicles per plot and weight of 1000 grains. Spikelet sterility was not affected by the application of $N$ in different stages or doses, by cold treatment or their interaction, but the cold

Instituto Nacional de Investigación Agropecuaria (INIA), Treinta y Tres. Ruta 8, km 286, Treinta y Três, Uruguay.

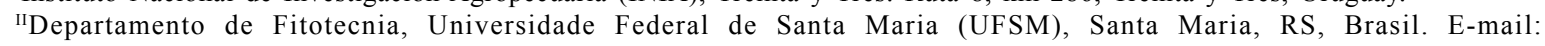
emarchezan@terra.com.br.*Autor para correspondência.

IIIDepartamento de Solos, UFSM, Santa Maria, RS, Brasil. 
treatment affected temporally the SPAD index with delaying panicle emerge. It is not necessary to modify the $N$ applications for this variety in Uruguay.

Key words: flooded rice, low temperature, SPAD index.

\section{INTRODUÇÃO}

O nitrogênio $(\mathrm{N})$ é um dos macronutrientes essenciais para a obtenção de alta produtividade de grãos de arroz e um dos mais estudados. Entretanto, ainda existem aspectos desconhecidos na sua interação com o ambiente e a utilização pela planta. Apesar do controle da maioria das variáveis de manejo da lavoura, as condições climáticas, principalmente temperatura e radiação solar, são essenciais para obtenção de resposta ao nutriente e alta produtividade de grãos. Na região produtora de arroz do Sul do Rio Grande do Sul (RS) e leste do Uruguai, é necessário aplicar nitrogênio $(\mathrm{N})$, já que a quantidade fornecida pelo solo desse nutriente não é suficiente para suprir as necessidades das plantas. As doses são determinadas em experimentos de campo. A recomendação de aplicação de $\mathrm{N}$ deve considerar a dose adequada e, também, a época de aplicação, já que o N é um nutriente transferido facilmente do sistema de produção por diversos mecanismos (FAGERIA \& STONE, 2003).

Trabalhos realizados pelo Instituto de Pesquisa Internacional do Arroz (IRRI), e na Austrália determinaram que a esterilidade de espiguetas ocasionada por temperatura baixa é aumentada por doses altas de N aplicadas (HEENAN, 1984; HAQUE, 1988; HAYASHI et al., 2000; GUNAWARDENA et al., 2003). No leste do Uruguai, DEAMBROSI et al. (1997) determinaram probabilidade de $20 \%$ (um em cada cinco anos) de ocorrerem médias descendais de temperaturas médias do ar inferiores a $15^{\circ} \mathrm{C}$ no período coincidente com a fase reprodutiva das plantas de arroz. STEINMETZ et al. (1997) estudaram os riscos de ocorrência de temperaturas baixas na mesma fase em oito localidades do Sul do Brasil e duas no Uruguai, sendo Treinta y TrEs, no Uruguai, a que apresentou os maiores riscos.

No Japão e na Austrália tem sido realizados experimentos com o objetivo de determinar o momento ótimo de aplicação de $\mathrm{N}$ dentro dos estádios da fase vegetativa ou reprodutiva e os efeitos na suscetibilidade à baixa temperatura na fase reprodutiva. No Japão, estudando o efeito do $\mathrm{N}$ na suscetibilidade ao frio na fase reprodutiva, SATAKE et al. (1987) dividiram a fase mais sensível ao frio (emborrachamento, entre R0 e R2, segundo a escala de COUNCE et al., 2000) em três estádios, sendo o mais sensível o período entre a diferenciação das espiguetas até o estádio de jovem micróspora Esse foi o estádio em que a aplicação de $\mathrm{N}$ provocou mais esterilidade de espiguetas. Resultados similares também foram obtidos por HAYASHI et al. (2000). Já GUNAWARDENA et al. (2003) trabalharam na fase vegetativa e na fase reprodutiva e encontraram que, independentemente da fase, doses únicas originam alta esterilidade de espiguetas. As aplicações de altas doses de $\mathrm{N}$, tanto na fase vegetativa, quanto reprodutiva, determinam um maior número de perfilhos e grãos por panícula, diminuindo a disponibilidade imediata de assimilados no momento de enchimento de grãos de pólen e ocasionando um aumento de esterilidade de espiguetas (GUNAWARDENA et al., 2003; GUNAWARDENA \& FUKAI, 2005).

As condições climáticas mudam de região para região, sendo necessário estudar localmente os efeitos das épocas e doses de aplicação de $\mathrm{N}$, tanto na fase vegetativa, quanto na reprodutiva, na suscetibilidade à baixa temperatura aplicada na fase reprodutiva. O objetivo do presente trabalho foi determinar o efeito das épocas e das doses de aplicação de $\mathrm{N}$ em estádios da fase vegetativa e da fase reprodutiva sobre a suscetibilidade da planta de arroz à temperatura baixa na fase reprodutiva.

\section{MATERIAL E MÉTODOS}

Os experimentos foram instalados no ano agrícola 2007/08 com a cultivar 'INIA Olimar' em casa de vegetação do Instituto Nacional de Investigação (INIA), INIA Treinta y Tres, Treinta y Tres, Uruguai. O solo destinado aos experimentos foi retirado do campo experimental de arroz do INIA Treinta y TrEs. Os resultados da análise química de solos foram, em média, os seguintes: $\mathrm{pH}\left(\mathrm{H}_{2} \mathrm{O}\right), 6,1$; M.O. $\left(\mathrm{g} \mathrm{kg}^{-1}\right), 2,79$ (adequada); P (Ac. Cítrico $\mu \mathrm{P} \mathrm{g}^{-1}$ ), 4,40 (baixo); K (cmol $\left.\mathrm{kg}^{-1}\right), 0,22$ (adequado), areia $270\left(\mathrm{~g} \mathrm{~kg}^{-1}\right)$, silte $470\left(\mathrm{~g} \mathrm{~kg}^{-1}\right) \%$ e argila $260\left(\mathrm{~g} \mathrm{~kg}^{-1}\right) \%$, enquadrado na Unidade de Solos "La Charqueada" (ALTAMIRANO, 1979).

Em novembro de 2007, sementes da cultivar 'INIA Olimar' foram embebidas por 24 horas em água da torneira e, em seguida, semeadas no solo acondicionado em vasos plásticos de 10 litros, com $10 \mathrm{~kg}$ de solo. Depois do desbaste, permaneceram oito plântulas de arroz por vaso. Aplicou-se a seguinte quantidade como nutriente na semeadura: $8 \mathrm{mg} \mathrm{kg}^{-1} \mathrm{de}$ solo de $\mathrm{N}, 20,4 \mathrm{mg} \mathrm{kg}^{-1}$ de solo de $\mathrm{P}_{2} \mathrm{O}_{5}$ como fosfato de amônio (DAP) e 9,6 $\mathrm{mg} \mathrm{kg}^{-1}$ de solo de $\mathrm{K}_{2} \mathrm{O}$ aplicado como cloreto de potássio $(\mathrm{KCl})$. $\mathrm{O}$ solo do vaso foi mantido úmido colocando-se água, quando era necessário, até a quarta folha, quando então foi alagado, 
deixando-se uma lâmina de água de $3 \mathrm{~cm}$, a qual foi aumentada, na medida em que as plantas foram crescendo, até atingir $5 \mathrm{~cm}$.

Realizou-se um experimento bifatorial em delineamento inteiramente casualizado (fator A: épocas ou doses de aplicação de $\mathrm{N}$ e fator $\mathrm{B}$ : tratamentos de temperatura: com e sem frio), com quatro repetições. No experimento 1, os tratamentos consistiram da aplicação de uma dose total em cobertura de $60 \mathrm{~kg}$ de N $\mathrm{ha}^{-1}$, sendo $30 \mathrm{~kg} \mathrm{ha}^{-1}$ aplicados em diferentes estádios de desenvolvimento da fase vegetativa (V4, V5, V6, V7 e V8) e mais $30 \mathrm{~kg} \mathrm{ha}^{-1}$ na fase reprodutiva em R0; um tratamento, que recebeu $30 \mathrm{~kg} \mathrm{ha}^{-1} \mathrm{em} \mathrm{V4}$ e mais $30 \mathrm{~kg}$ $\mathrm{ha}^{-1} \mathrm{em} \mathrm{R}$; outro tratamento onde aplicou-se $30 \mathrm{~kg} \mathrm{ha}^{-1}$ em V5 acrescido de $30 \mathrm{~kg} \mathrm{ha}^{-1} \mathrm{R} 1+4$ dias; mais uma testemunha sem $\mathrm{N}$ em cobertura. No experimento 2, variou-se a dose de N, aplicando-se 0, 23, 46 e $69 \mathrm{~kg}$ de $\mathrm{N}$ ha ${ }^{-1}$ em V4 e outros $23 \mathrm{~kg}$ de $\mathrm{N} \mathrm{ha}^{-1}$ no estádio $\mathrm{R} 0$, além de outros três tratamentos que receberam $23 \mathrm{~kg}$ de $\mathrm{N} a^{-1}$ em V4 e 0 , 46 e $69 \mathrm{~kg}$ de $\mathrm{N} \mathrm{ha}^{-1}$ em R0, mais uma testemunha sem $\mathrm{N}$ em cobertura. A quantidade de uréia aplicada nos diferentes tratamentos foi calculada de acordo com a superfície dos vasos.

Os vasos com as plantas foram mantidos todo o tempo na casa de vegetação. Quando o colmo principal chegou ao estádio onde o colar da folha bandeira ficou próximo ao colar da folha anterior (entre os estádios R1 e R2), aplicou-se o tratamento de frio aos vasos correspondentes. Para a determinação dos estádios de desenvolvimento do arroz, utilizou-se a escala de COUNCE et al. (2000), marcando uma planta com anéis de arame colorido no colmo principal em 16 baldes. O tratamento foi realizado sob temperatura de $12,5^{\circ} \mathrm{C}$ por sete horas durante quatro noites na câmara de frio. Os dados para a realização desse tratamento foram coletados na base de dados da estação agrometeorológica do INIA Treinta y TrEs, que mantém registros desde 1972. A manutenção da temperatura dentro da casa de vegetação foi feita automaticamente, mantendo-se temperaturas entre $20^{\circ} \mathrm{C} \mathrm{e} 35^{\circ} \mathrm{C}$. Quando a temperatura era menor que $20^{\circ} \mathrm{C}$, o sistema automaticamente ligava a calefação e, quando a temperatura era maior que $35^{\circ} \mathrm{C}$, os aspersores eram acionados, o que nem sempre foi eficiente para reduzir a temperatura até o valor desejado.

Os parâmetros avaliados foram: a percentagem de esterilidade de espiguetas, o índice SPAD (medida indireta do teor de clorofila), realizado aos três, 10 e 16 dias, após o tratamento do frio no estádio R2-R3 no terço superior da folha bandeira de 10 plantas no colmo principal, a produtividade de grãos por vaso $(\mathrm{g})$, o número de panículas por balde e a massa de mil grãos ( $\mathrm{g}$ ). A determinação dos componentes do rendimento foi realizada em 10 panículas por vaso.
Para a análise estatística, foi utilizado o software estatístico MSTAT 4, da Universidade de Michigan (EUA), aplicando-se o teste F para as variáveis em estudo e, quando significativo (5\%), foi feita a separação de médias pelo teste de Tukey a $5 \%$. Para a análise da percentagem de esterilidade de espiguetas, foi utilizada a transformação arco seno (GOMEZ \& GOMEZ, 1984).

\section{RESULTADOS E DISCUSSÃO}

Não houve efeito significativo das épocas nem das doses de aplicação de $\mathrm{N}$ sobre a esterilidade de espiguetas (Tabelas 1 e 2). Esses resultados são diferentes dos encontrados na literatura, já que a literatura reporta que as aplicações de $\mathrm{N}$, tanto na fase vegetativa, quanto na reprodutiva, provocam maior esterilidade de espiguetas quando as plantas são submetidas a frio na fase reprodutiva (HEENAN, 1984; HAQUE, 1988; HAYASHI et al., 2000; GUNAWARDENA et al, 2003). Um aspecto importante a ser considerado é a duração do período de frio, já que neste experimento as plantas foram submetidas ao frio que normalmente ocorre na região, enquanto outros pesquisadores usaram 24 horas de frio durante um número diferente de dias: HEENAN (1984) usou $12^{\circ} \mathrm{C}$ durante quatro dias; HAQUE (1988), $15^{\circ} \mathrm{C}$ durante cinco dias; HAYASHI et al (2000), $12^{\circ} \mathrm{C}$ durante quatro dias e GUNAWARDENA et al. (2003), 18/13 ${ }^{\circ} \mathrm{C}$, dia/noite durante cinco dias. Outro aspecto é que os trabalhos citados anteriormente usaram doses de $\mathrm{N}$ maiores que as usadas no presente trabalho: HEENAN (1984) usou 75 e $150 \mathrm{~kg} \mathrm{ha}^{-1}$ de N, HAQUE (1988) usou 10, 40 e 80mg $\mathrm{kg}^{-1}$ de N, HAYASHI et al (2000) usou $80 \mathrm{mg} \mathrm{kg}^{-1} \mathrm{de} \mathrm{N} \mathrm{e}^{-}$ GUNAWARDENA et al (2003) usou $150 \mathrm{~kg} \mathrm{ha}^{-1}$. No presente experimento, foram utilizadas doses de $\mathrm{N}$ recomendadas na região, as quais são consideradas baixas se comparadas com as citadas anteriormente. Isso pode explicar, em parte, a não-ocorrência de efeitos pelos tratamentos aplicados. Também é importante salientar que a falta de respostas aos tratamentos na esterilidade de espiguetas pode ser devido às temperaturas altas antes e depois da aplicação dos tratamentos de frio, o que, de acordo com SATAKE (1969), pode minimizar o efeito do frio na esterilidade de espiguetas.

Ainda pode-se considerar, na explicação dos resultados obtidos neste experimento, os diferentes momentos em que os genótipos utilizados nos trabalhos têm mais sensibilidade ao frio. Assim, HEENAN (1984), trabalhando com as variedades Calrose e Inga, encontraram o seguinte resultado: o dano por frio para Calrose foi maior quando a distância entre as aurículas das folhas bandeira e a penúltima 
Doses e épocas de aplicação de nitrogênio na suscetibilidade do arroz à temperatura baixa na fase reprodutiva.

Tabela 1 - Efeito da época de aplicação de nitrogênio na resposta a frio $\left(12,5^{\circ} \mathrm{C}\right.$, por quatro noites, sete horas por noite do arroz da cultivar 'Olimar' medido pela esterilidade de espiguetas, pela produtividade de grãos por vaso, pelo número de grãos por panícula e pela massa de mil grãos (Experimento 1). INIA Treinta y Tres, Treinta y Tres, Uruguai, 2008.

\begin{tabular}{|c|c|c|c|c|}
\hline \multirow{2}{*}{ Tratamentos } & Esterilidade de espiguetas & Produtividade de grãos & Grãos por Panícula & Massa de mil grãos \\
\hline & $\%$ & $\mathrm{~g} \mathrm{vaso}^{-1}$ & Número & $\mathrm{g}$ \\
\hline Sem nitrogênio & $23,4(\mathrm{~ns})$ & $33,7 b^{(1)}$ & $76 \mathrm{a}$ & $24,9 \mathrm{a}$ \\
\hline $\mathrm{V} 4 / \mathrm{R} 0^{(2)}$ & 13,8 & $60,5 \mathrm{a}$ & 93 a & $25,4 \mathrm{a}$ \\
\hline $\mathrm{V} 5 / \mathrm{R} 0$ & 13,5 & $56,5 \mathrm{ab}$ & $92 \mathrm{a}$ & $26,1 \mathrm{a}$ \\
\hline V6/R0 & 15,9 & $57,5 \mathrm{ab}$ & 93 a & $26,1 \mathrm{a}$ \\
\hline V7/R0 & 19,5 & $53,5 \mathrm{ab}$ & $83 \mathrm{a}$ & $25,2 \mathrm{a}$ \\
\hline V8/R0 & 16,8 & $53,5 \mathrm{ab}$ & $85 \mathrm{a}$ & 26,0 a \\
\hline $\mathrm{V} 4 / \mathrm{R} 1$ & 13,6 & $51,8 \mathrm{ab}$ & $85 \mathrm{a}$ & $26,1 \mathrm{a}$ \\
\hline $\mathrm{V} 4 / \mathrm{R} 2$ & 13,2 & $45,7 \mathrm{ab}$ & $83 \mathrm{a}$ & $25,8 \mathrm{a}$ \\
\hline Sem frio & $17,6^{(\mathrm{ns})}$ & $51,0^{(\mathrm{ns})}$ & $86^{(\mathrm{ns})}$ & $25,8^{(\mathrm{ns})}$ \\
\hline Com frio & 14,8 & 52,2 & 87 & 25,6 \\
\hline Média & 16,2 & 51,6 & 86 & 25,7 \\
\hline CV $(\%)$ & 54,7 & 21,1 & 13,3 & 2,3 \\
\hline
\end{tabular}

1) Médias nas colunas não ligadas pela mesma letra diferem entre si pelo teste de Tukey a 5\% de probabilidade de erro;

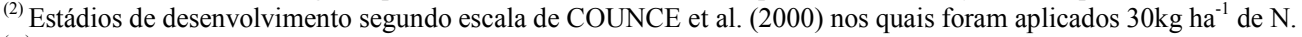

${ }^{\text {(ns) }}$ Médias não diferem pelo Teste $\mathrm{F}(\mathrm{P}=0,05)$.

folha estava entre $-1 \mathrm{e}+3 \mathrm{~cm}$, enquanto que, para Inga, a maior sensibilidade ocorreu quando a distância entre as aurículas situava-se em $+6 \mathrm{~cm}$. A cultivar 'INIA Olimar' utilizada no presente trabalho é de recente liberação à produção comercial. Portanto, não se conhece o momento de maior sensibilidade ao frio e, assim, a aplicação dos tratamentos de frio pode não ter ocorrido no momento de maior sensibilidade da planta. Além disso, a variabilidade observada entre as unidades experimentais para esterilidade de espiguetas foi muito alta, dificultando encontrar diferenças entre os tratamentos.

Tabela 2 - Efeito da época de aplicação de nitrogênio na resposta a frio $\left(12,5^{\circ} \mathrm{C}\right.$, por quatro noites, sete horas por noite $)$ da cultivar 'Olimar', medida pelo índice SPAD aos três e 10 dias após o tratamento (DAT) de frio e do número de panículas por vaso aos 87 e 92 dias após a emergência (DAE) (Experimento 1). INIA Treinta y Tres, Treinta y Tres, Uruguai, 2008 .

\begin{tabular}{|c|c|c|c|c|}
\hline \multirow{2}{*}{ Tratamentos } & \multirow{2}{*}{$\begin{array}{c}\text { Índice SPAD } \\
3 \text { DAT }\end{array}$} & \multirow{2}{*}{$\begin{array}{c}\text { Índice SPAD } \\
10 \text { DAT }\end{array}$} & \multicolumn{2}{|c|}{--------Número de panículas por vaso------- } \\
\hline & & & $87 \mathrm{DAE}$ & $92 \mathrm{DAE}$ \\
\hline Sem nitrogênio & $29,3 \mathrm{bc}^{(1)}$ & $31,3 \mathrm{abc}$ & $7 \mathrm{ab}$ & $20 \mathrm{ab}$ \\
\hline $\mathrm{V} 4 / \mathrm{R} 0^{(2)}$ & 28,5 c & $31,0 \mathrm{abc}$ & $11 \mathrm{ab}$ & $27 \mathrm{a}$ \\
\hline V5/R0 & $27,7 \mathrm{c}$ & $30,8 \mathrm{abc}$ & $8 \mathrm{ab}$ & $25 \mathrm{ab}$ \\
\hline $\mathrm{V} 6 / \mathrm{R} 0$ & $28,3 \mathrm{c}$ & $32,7 \mathrm{ab}$ & $11 \mathrm{ab}$ & $26 \mathrm{ab}$ \\
\hline $\mathrm{V} 7 / \mathrm{R} 0$ & $29,0 \mathrm{bc}$ & 29,2 bc & $4 \mathrm{ab}$ & $18 \mathrm{ab}$ \\
\hline $\mathrm{V} 8 / \mathrm{R} 0$ & $29,1 \mathrm{bc}$ & $27,5 \quad \mathrm{c}$ & $1 \mathrm{~b}$ & $16 \mathrm{~b}$ \\
\hline $\mathrm{V} 4 / \mathrm{R} 1$ & $32,8 \mathrm{ab}$ & $33,5 \mathrm{a}$ & $14 \mathrm{a}$ & $26 \mathrm{ab}$ \\
\hline $\mathrm{V} 4 / \mathrm{R} 1+4$ & $34,2^{\mathrm{a}}$ & $34,3 \mathrm{a}$ & $13 \mathrm{ab}$ & $22 \mathrm{ab}$ \\
\hline Sem frio & $30,3 *$ & $31,4^{\text {(ns) }}$ & $10^{*}$ & $22^{(\mathrm{ns})}$ \\
\hline Com frio & 29,4 & 31,2 & 7 & 23 \\
\hline Média & 29,8 & 31,3 & 9 & 22 \\
\hline CV (\%) & 6,1 & 5,7 & 65,1 & 19,8 \\
\hline
\end{tabular}

${ }^{(1)}$ Médias nas colunas não ligadas pela mesma letra diferem entre si pelo teste de Tukey a 5\% de probabilidade de erro;

${ }^{(2)}$ Estádios de desenvolvimento segundo escala de Counce et al. (2000) nos quais foram aplicados $30 \mathrm{~kg} \mathrm{ha}^{-1} \mathrm{de} \mathrm{N}$;

* Média de tratamento por frio diferem pelo Teste $\mathrm{F}(\mathrm{P}=0,05)$;

(ns) Médias não diferem pelo Teste $\mathrm{F}(\mathrm{P}=0,05)$. 
No experimento 1, verificou-se efeito simples da época de aplicação de $\mathrm{N}$ na produtividade de grãos por vaso, no número de grãos por panícula e na massa de mil grãos (Tabela 1). A aplicação de $\mathrm{N}$ no estádio V4 proporcionou a produtividade mais alta e superior à testemunha, mas não foram registradas diferenças entre os outros tratamentos com aplicação de N (Tabela 1). $\mathrm{O}$ efeito do $\mathrm{N}$ provocando maior número de panículas ao final da floração (92DAE) (Tabela 3) no estádio V4 explica a maior produtividade de grãos encontrados neste tratamento. A aplicação de $\mathrm{N}$ no estádio V4 seguramente provocou maior perfilhamento. Já no experimento 2 a produtividade por vaso e a massa de mil grãos não foram afetadas pelo frio nem ocorreu interação entre os dois fatores. Apesar do maior número de grãos obtido no tratamento sem aplicação de frio, isso não se refletiu na produtividade (Tabela 2). Os altos coeficientes de variação obtidos para esterilidade de espiguetas e também para o número de grãos por panícula explicam, em parte, esse resultado.

No experimento 1, as leituras feitas com o clorofilômetro (índice SPAD) na folha bandeira, três dias após do tratamento com frio (DAT), apresentaram efeitos simples significativos, tanto da época de aplicação de $\mathrm{N}$, quanto do tratamento de temperatura (Tabela 3). Entretanto, a leitura aos 10DAT não apresentou resultados significativos, indicando que as plantas se recuperam do estresse de frio. No experimento 2, o efeito do frio provocou diminuição no índice SPAD aos três DAT e aos 10DAT (Tabela 2), recuperando-se aos 16 dias $(33,9$, com frio e 33,6 sem frio).

Na tabela 3, é apresentada a comparação de médias do índice SPAD pelo teste de Tukey aos três e aos 10DAT, quando o tratamento de aplicação de N no estádio R1+4 dias apresentou maior valor, seguramente, devido à realização da leitura pouco depois da aplicação de N. Observa-se também o aumento no índice SPAD entre os registros aos três DAT $(30,3)$ e aos 10 DAT $(31,4)$ (R2-R3 e R5, respectivamente). Isso também ocorreu no experimento 2, em que o índice SPAD foi incrementado entre a leitura aos três DAT $(28,9)$ e 10DAT $(32,4)$. Isso possivelmente deve-se à translocação de $\mathrm{N}$ para a folha bandeira. Os registros foram maiores aos três e aos 10DAT nos estádios reprodutivos ( $\mathrm{R} 1$ e $\mathrm{R} 1+4)$, no experimento 1 , possivelmente porque estão próximos das aplicações de N.

Nos dois experimentos, o tratamento de temperatura afetou o número de panículas por vaso aos 87 dias da emergência (Tabelas 3 e 2). O frio possivelmente provocou uma diminuição na atividade fotossintética (KUK et al, 2003) inferida pelo clorofilômetro, o que ocasionou a diminuição na produção de assimilados e, portanto, provocou um atraso na emergência de panículas aos 87 dias, recuperando-se aos 92 dias. Em nível celular, segundo LYONS (1973), o frio provoca perda na fluidez das membranas, tanto das células, quanto das organelas (cloroplastos, ribossomas, etc), mudando a funcionalidade delas. As proteínas do centro de reação da fotossíntese e do transporte de elétrons estão localizadas nas membranas dos tilacóides dos cloroplastos (BERRY \& BJORKMAN, 1980). Os processos enzimáticos, como a cadeia de transportadores de elétrons nos tilacóides, a fotofosforilação e as enzimas do ciclo de Calvin, são afetados pelo frio (OQUIST, 1983). Portanto, todos esses

Tabela 3 - Efeito de temperaturas baixas $\left(12,5^{\circ} \mathrm{C}\right.$, por quatro noites, sete horas por noite) em plantas de arroz da cultivar 'INIA Olimar' na esterilidade de espiguetas, na produtividade de grãos, no número de grãos por panícula, na massa de mil grãos e na medida indireta do teor de clorofila (Índice SPAD) verificado aos três e 10 dias após o tratamento (DAT) de frio e número de panículas/balde aos 87 e 92 dias depois da emergência (DAE) de plântulas (Experimento 2). INIA Treinta y Tres, Treinta y Tres, Uruguai, 2008.

\begin{tabular}{|c|c|c|c|c|}
\hline \multirow{2}{*}{ Avaliações } & \multicolumn{2}{|c|}{----------Tratamentos---------- } & \multirow{2}{*}{ Média } & \multirow{2}{*}{$\mathrm{CV}(\%)$} \\
\hline & Sem frio & Com frio & & \\
\hline Esterilidade de espiguetas (\%) & $19,1^{\text {ns }}$ & 23,2 & 21,2 & 66,4 \\
\hline Produtividade de grãos $\left(\mathrm{kg} \mathrm{vaso}^{-1}\right)$ & $58,3^{\text {ns }}$ & 55,5 & 56,9 & 17,8 \\
\hline Número de grãos por panícula & $90 *$ & 80 & 85 & 21,3 \\
\hline Massa de mil grãos $(\mathrm{g})$ & $26,7^{\mathrm{ns}}$ & 26,5 & 26,6 & 2,2 \\
\hline Índice SPAD 3DAT & $29,7 *$ & 28 & 28,9 & 5,3 \\
\hline Índice SPAD 10DAT & $32,8^{*}$ & 32 & 32,4 & 3,2 \\
\hline Número de panículas por vaso aos 87DAE & $18 *$ & 15 & 16 & 24,7 \\
\hline Número de panículas por vaso aos 92DAE & $29^{\mathrm{ns}}$ & 28 & 28 & 10 \\
\hline
\end{tabular}

* Médias diferem pelo teste $\mathrm{F}(\mathrm{P}=0,05)$.

${ }^{\text {ns }}$ Médias não diferem pelo Teste $\mathrm{F}(\mathrm{P}=0,05)$. 
mecanismos da fotossíntese são afetados pelo frio, provocando uma redução desta e também a produção de assimilados.

Embora o efeito da adubação nitrogenada sobre a sensibilidade ao frio de plantas de arroz seja reconhecido na literatura, pode-se considerar que as doses e épocas de aplicação de nitrogênio, usualmente empregadas na região produtora do Uruguai, não devem exercer efeito significativo sobre a sensibilidade ao frio que normalmente ocorre nessa região, durante a fase reprodutiva do arroz, cultivar 'INIA Olimar'. Isto significa que não há necessidade de ajustes da adubação nitrogenada mesmo quando há expectativa de ocorrência de frio.

\section{CONCLUSÕES}

A esterilidade de espiguetas da cultivar 'INIA Olimar' não é afetada pela época ou pelas doses de $\mathrm{N}$ utilizadas nem pelo frio aplicado na fase reprodutiva, considerando os limites utilizados neste trabalho. $\mathrm{O}$ frio influencia temporariamente o teor de clorofila medido por meio do índice SPAD, o que ocasiona atraso na emergência de panículas.

\section{AGRADECIMENTOS}

Ao Programa de Estudantes Convênio de PósGraduação (PEC/PG) da Coordenação de Aperfeiçoamento de Pessoal de Nível Superior (CAPES), pela bolsa concedida a Ramón Méndez Larrosa; ao Conselho Nacional de Desenvolvimento Científico e Tecnológico (CNPq), pela concessão de bolsa de produtividade em pesquisa a Enio Marchesan; aos técnicos e funcionários do Instituo Nacional de Investigación Agropecuária em Treinta Y Tres, Uruguai (INIA), pela ajuda nos experimentos realizados; à Dra. Walkyria Bueno Scivittaro da EMBRAPA Clima temperado, pelas sugestões de redação do texto.

\section{REFERÊNCIAS}

ALTAMIRANO, A. Carta detallada de suelos. Campo experimental Paso de la Laguna. Montevideo: Ministerio de Agricultura y Pesca. Dirección de Suelos y Fertilizantes, 1979. 1 Mapa, Escala 1:2500.

BERRY, J.; BJORKMAN, O. Photosynthetic response and adaptations to temperature in higher plants. Annual Review of Plant Physiology, Palo Alto, v. 31, p.491-543, 1980.

COUNCE, P.A. et al. A uniform, objective and adaptative system for expressing rice development. Crop Science, n.40, p.436-443, 2000 .

DEAMBROSI, E. et al. Estrategia en la producción de arroz para un mejor aprovechamiento de las principales variables climáticas. Treinta y Três: INIA Treinta y Três, 1997. Serie Técnica 89. 16p.

FAGERIA, N.K.; STONE, L.F. Manejo do nitrogênio. In: FAGERIA, N.K. et al. (Eds.). Manejo da fertilidade do solo para o arroz irrigado. Santo Antonio de Goiás, GO: EMBRAPA Arroz e Feijão, 2003. p.51-94.

GOMEZ, K.A.; GOMEZ, A.A. Statistical procedures for agricultural research. 2.ed. Singapore: John Wiley \& Sons, 1984. 680p.

GUNAWARDENA, T.A.; FUKAI, S. The interaction of nitrogen application and temperature during reproductive stage on spikelet sterility in field-grown rice. Australian Journal of Agricultural Research, Melbourne, v.56, p.625-636, 2005. Disponível em: <http://www.publish.csiro.au/paper/ AR04099.htm >. Doi: 10.1071/AR04099

GUNAWARDENA, T.A. et al. Low temperature induced spikelet sterility in rice. I. Nitrogen fertilization and sensitive reproductive period. Australian Journal of Agricultural Research, Melbourne, v.54, p.937-946, 2003. Disponível em: <http://www.publish.csiro.au/paper/AR03075.htm>. Doi: 10.1071/AR03075.

HAQUE, M.Z. Effect of nitrogen, phosphorus and potassium on spikelet sterility induced by low temperature at the reproductive stage of rice. Plant and Soil, Dordrecht, v.109, p.31-36; 1988 .

HAYASHI, T. et al. Effects of high nitrogen supply on the susceptibility to coolness at the young microspore stage in rice (Oryza sativa L.). Plant Production Science, Tokyo, v.3, n. 3, p.323-327, 2000 .

HEENAN, D.P. Low-temperature induced floret sterility in the rice cultivars Calrose and Inga as influenced by nitrogen supply. Australian Journal of Experimental Agriculture and Animal Husbandry, Melbourne, v.24, p.255-259, 1984. Disponível em: <http://www.publish.csiro.au/paper/ EA9840255>. Doi: 10.1071/EA9840255.

KUK et al. Antioxidative enzymes offer protection from chilling damage in rice plants. Crop Science, Madison, v.43, p.21092117,2003

LYONS, J.M. Chilling injury in plants. Annual Review of Plant Physiology, Palo Alto, v.24, p.445-466, 1973. Disponível em: <http://arjournals.annualreviews.org/doi/abs/ 10.1146\%2Fannurev.pp.24.060173.002305>. Doi:10.1146/ annurev.pp.24.060173.002305

OQUIST, G. Effects of low temperature on photosynthesis. Plant, Cell and Environment, v.6, n.4, p.281-300, 1983.

SATAKE, T. Research on cool injury of paddy rice plants in Japan. Japan Agricultural Research Quarterly, v.4, n.4, p.5-10, 1969 .

SATAKE, T. al. Male sterility caused by cooling treatment at young microspore stage in rice plants. XXVI. Effect of water temperature and nitrogen application before the critical stage on sterility induced by cooling at the critical stage. Japanese Journal of Crop Science, v.56, n.3, p.404-410, 1987.

STEINMETZ, S. et al. Risco de ocorrência de frio durante o periodo reprodutivo do arroz irrigado em regiões produtoras do Rio Grande do Sul e do Uruguai. In: REUNIÃO DA CULTURA DO ARroZ, IRrigADO, 22., 1997, Camburiu. Anais... Camboriu: EPAGRI-IRGA-EMBRAPA/CPTACT-CNPq, 1997. p.114-117. 